\title{
Salas de coordenação de projetos em BIM: proposta de um método de avaliação
}

\author{
BIM design coordination rooms: proposal of an assessment \\ method
}

Miriam Roux Azevedo Addor
Eduardo Toledo Santos
Resumo
BIM apresenta inúmeras vantagens quando comparada àquela baseada em CAD
tridimensional que contém todas as informações da documentação
tradicional 2D, e outras mais, num formato passível de processamento
necessidade de modificações na infraestrutura física das salas de reuniões de
coordenação para a obtenção do máximo benefício que o BIM pode proporcionar.
Este trabalho visa ao desenvolvimento de um método de avaliação de salas de
coordenação de projetos em BIM. Para a avaliação da qualidade de leiautes das
salas foram propostos dez critérios e métricas. Com a finalidade de estabelecer
uma relação de importância entre todos os critérios propostos foi aplicado o
método AHP de decisão multicritério, baseado na análise de comparações em
pares. Para a validação dos resultados foram analisados e avaliados 14 leiautes
diferentes para uma mesma sala. O método proposto mostrou-se coerente como
estratégia de avaliação e produziu resultados lógicos, sendo possível identificar as
melhores alternativas. Os critérios e métricas apresentados são úteis para o projeto
ou adaptação de ambientes para atender os usuários de salas de reuniões de
projetos baseados em BIM.

Miriam Roux Azevedo Addor Universidade de São Paulo São Paulo - SP - Brasil

Eduardo Toledo Santos Universidade de São Paulo São Paulo - SP - Brasil

Recebido em 17/04/16 Aceito em 24/01/17
Palavras-chave: Espaços interativos. Reuniões de coordenação de projetos. Visualização. AHP. Modelagem da Informação da Construção. BIM.

\begin{abstract}
Building Information Modeling (BIM) focuses on a tridimensional model that contains all the information of a traditional $2 D$ documentation, among others, in a format able to be processed by a computer in a more useful way. BIM design coordination has many advantages compared to those based on $2 D C A D$.

However, considering the drastic change in the design representation, there is a need for modifications in the physical infrastructure of coordination meeting rooms to reach all the potential benefits of BIM. This research aims to develop a method for evaluating BIM coordination rooms. Ten criteria and metrics for evaluating the quality of the layout of BIM coordination rooms were proposed. To establish the relative importance among all the proposed criteria, the AHP method of multi-criteria decision based on pair comparisons analysis was adopted. To validate the results, fourteen different layouts for the same room were analysed and evaluated. The proposed method was considered coherent as an evaluation strategy and, therefore the best alternatives could be identified. The criteria and metrics presented are useful for designing or adapting spaces for meeting the needs of BIM-based design coordination room users.
\end{abstract}

Keywords: Interactive design spaces. Design coordination meetings. Visualization, AHP. Building Information Modeling. BIM. 


\section{Introdução}

A Modelagem da Informação da Construção (BIM) é o processo de produção, uso e atualização de um modelo de informações da edificação, potencialmente durante todo o seu ciclo de vida (SANTOS, 2012). Segundo Santos (2012), esse modelo, além da geometria da construção, contém numerosas informações sobre seus diferentes aspectos, podendo abranger todas as disciplinas envolvidas em um empreendimento.

Dentro da área da Tecnologia da Informação aplicada à Construção Civil, o BIM tem sido, há vários anos, o tema principal de pesquisa, no Brasil e no exterior, em especial sobre os impactos causados e as mudanças necessárias para a implantação desse novo processo. No entanto, pesquisas sobre as mudanças necessárias nos ambientes físicos onde se desenvolve a etapa de projeto e, mais especificamente, a atividade de coordenação ainda são muito raras. No ciclo de vida da construção a etapa em que o BIM é mais comumente usado atualmente é a do desenvolvimento do projeto ("design"), na qual estão seus usos mais rotineiros (autoria de projetos, visualização, detecção de interferências, coordenação, etc.). Apesar de o processo BIM se prestar bem à engenharia simultânea ou colaborativa realizada a distância, dada a natureza tecnológica das ferramentas que o suportam, a prática de mercado ainda é a realização de reuniões de coordenação presenciais, em salas nem sempre adaptadas ao BIM (GOLPARVAR-FARD et al., 2006; LOPEZ et al., 2015). Considerando esse contexto, este trabalho enfoca as reuniões de caráter presencial e tem como meta contribuir para a implantação de salas de reunião adequadas à coordenação de projetos desenvolvidos em BIM. O público-alvo são os profissionais que trabalham na área de projetos e que estão se especializando em BIM, bem como os contratantes especificamente da área imobiliária, podendo ser estendido para projetos dos demais setores da construção civil. O contratante do setor imobiliário tem participação intensa durante as reuniões de projeto e, diante das restrições de gastos, necessita de alternativas de soluções com bom custobenefício. Dessa forma, reuniões com maior colaboração e instrumentadas para respostas mais ágeis são mais adequadas. Os primeiros usuários de BIM, há várias décadas, tiveram como principal objetivo o uso deste para visualização de projetos (EASTMAN et al., 2008). Atualmente, o BIM tem potencial para revolucionar a construção civil, alinhando-a, em termos de uso de tecnologia da informação, a outras indústrias. A adoção crescente de BIM tem ocorrido em muitos países (MCGRAW-HILL..., 2012, 2014).
Apesar de salas de coordenação em processo BIM já terem sido testadas e utilizadas em outros países, não se pode utilizar diretamente esses resultados no Brasil, dadas as diferenças culturais, tecnológicas e processuais de cada país. Nos Estados Unidos, por exemplo, em obras de maior porte, o fluxo do projeto é usualmente concluído na fase pré-executiva pelo projetista, e a fase de detalhamento e pré-fabricação é feita pelo subcontratado em obra. A análise dos conflitos entre especialidades geralmente ocorre dentro dos canteiros de obra, em "iRooms" dentro de trailers, ou nos escritórios dos subcontratados (SENESCU, 2011).

No Brasil, o setor de coordenação de projetos ainda se mostra incipiente nas iniciativas de atender à infraestrutura de salas de coordenação em BIM. Conforme a experiência dos autores, há algumas iniciativas isoladas nesse processo que utilizam telas de projeção, televisores, monitores, tablets e PCs na fase de projeto. As reuniões de coordenação de projetos tipicamente envolvem uma grande variedade e quantidade de dados (FISCHER et al., 2002). As salas que hoje se usam no Brasil para essa atividade são simples salas de reuniões, com mesa e cadeiras. Algumas vezes, utilizam-se telas com projetores comuns ou uma TV que se conecta a um notebook (ADDOR; SANTOS, 2014). Assim, existe uma lacuna na atual infraestrutura de salas de coordenação voltadas para o processo BIM no país.

À medida que o processo de trabalho muda, com a geração de modelos tridimensionais que contêm informações tanto sobre a forma da edificação como sobre materiais, componentes, estrutura e custos, o contexto de análise desses modelos também deve ser observado (OGUETA, 2012). Dentro desse novo contexto, além das informações que o modelo carrega, a forma como este é apresentado e seu caráter digital fazem com que a infraestrutura para atender a seus requisitos deva ser especial.

De acordo com centros de pesquisa que atuam na área há mais de vinte anos, como o Center for Integrated Facility Engineering (CIFE), da Universidade de Stanford, e o Computer Integrated Construction (CIC) Research Program, da PennState University, muitos são os benefícios de uma sala interativa de projetos, como dar capacidade às equipes para visualizar e interagir com as informações do projeto, fornecendo apoio à tomada de decisão (FISCHER et al., 2002).

Este trabalho foi desenvolvido com o objetivo de propor um avanço no que se refere à criação de 
espaços destinados à coordenação de projetos BIM no Brasil e procura entender os aspectos relacionados ao contexto de uso da sala e às necessidades e interfaces dos usuários. Para atender ao objetivo proposto, foi desenvolvido um método de avaliação de salas de coordenação de projetos baseados em BIM. O método de pesquisa incluiu a avaliação do processo de comunicação dentro de salas de coordenação e a proposta de critérios e métricas de avaliação, bem como seu teste em uso.

\section{Revisão bibliográfica}

A coordenação de projetos é uma atividade focada no gerenciamento das questões técnicas, prazo, qualidade, escopo e tomada de decisão em projeto, para atender às questões citadas e também à integração e compatibilização entre elas (MELHADO et al., 2005). Segundo Melhado et al. (2005), esse serviço deve ser exercido durante todo o processo de projeto e tem como objetivo fomentar a interatividade na equipe de projeto e melhorar a qualidade dos projetos desenvolvidos. Tal processo implica o gerenciamento da comunicação entre todos os envolvidos no projeto do empreendimento, tanto durante as reuniões de coordenação quanto fora delas.

Os espaços onde as reuniões de coordenação de projetos ocorrem podem ser físicos ou virtuais (LISTON; FISCHER; KUNZ, 2000) e são utilizados para compartilhamento de informações e para consultas e tomada de decisão. A tomada de decisão em projeto, na maioria das vezes, ainda é feita presencialmente (LISTON; FISCHER; KUNZ, 2000; LOPEZ et al., 2015). Em outros países, a adoção do processo BIM na fase de projeto e a disponibilidade de novas tecnologias estão levando os usuários a examinar recursos alternativos para a infraestrutura do espaço onde as reuniões são realizadas (LISTON; FISCHER; KUNZ, 2000; FRUCHTER, 2006; KU et al., 2008; LEICHT, 2009), apesar de a crescente disponibilidade de infraestrutura de internet possibilitar às equipes a execução de reuniões a distância.

Em estudo anterior realizado sobre vinte e seis reuniões de coordenação de projetos (ADDOR; SANTOS, 2014) com o objetivo de identificar as atividades que ocorrem com maior frequência dentro das salas de coordenação de projetos, identificou-se que $48 \%$ delas dizem respeito a visualizar plantas impressas por alguns ou por todos os participantes da reunião. Embora esse estudo tenha sido feito sobre reuniões em que se usa documentação impressa, de acordo com a quantidade de ações ocorridas, chegou-se à conclusão de que uma tela de projeção poderia suprir a maioria das ações mais frequentes nelas.

Dando continuidade ao estudo relatado, foram também observadas reuniões em processo BIM que resultaram na identificação das várias necessidades dos usuários em função da mudança de seu comportamento ante a nova tecnologia de comunicação. Essas necessidades serviram de base para a estruturação do método desenvolvido neste trabalho.

Na revisão bibliográfica identificou-se uma lacuna no conhecimento que existe em relação ao tema abordado. Poucos estudos foram realizados e os que foram identificados não exploram fatores considerados importantes neste trabalho, já que não são específicos para reuniões de coordenação de projetos em BIM.

\section{Método de pesquisa}

Para que os objetivos desta pesquisa pudessem ser alcançados, foi utilizada a abordagem de Pesquisa Construtiva (Constructive Research) (OYEGOKE, 2011). Kasanen, Lukka e Siitonen (1993) referem-se à abordagem construtiva como a resolução de problemas através da construção de um modelo, plano ou constructo. Nesse tipo de questionamento é essencial estreitar o problema e sua solução conjuntamente com um conhecimento teórico acumulado (KASANEN; LUKKA; SIITONEN, 1993).

O problema identificado neste estudo diz respeito à falta de infraestrutura adequada para apoio às atividades de coordenação de projetos com modelos em objetos paramétricos e tridimensionais, típicos do BIM, que difere da coordenação de projetos baseada na análise em papel (LISTON; FISCHER; KUNZ, 2000; LEICHT, 2009; GOLPARVAR-FARD et al., 2006).

A abordagem de pesquisa construtiva envolve o projeto de um artefato que deve ser baseado na interpretação do contexto da revisão de literatura e nos aspectos práticos dos problemas (OYEGOKE, 2011). Para tal, além do levantamento de literatura, foram utilizadas vinte e seis gravações em vídeo de reuniões de coordenação de projeto convencionais (baseadas em análise sobre papel) e de dez reuniões baseadas em processo BIM realizadas em estudo anterior (ADDOR; SANTOS, 2014). O resultado desse estudo é apresentado na parte seguinte deste trabalho. Nessas reuniões foi aplicado um método empírico e observacional chamado de análise de protocolo (protocol analysis) (JIANG; YEN; 2009), no qual se faz o registro do comportamento de pessoas em 
um espaço de tempo. Protocolos de projeto são geralmente utilizados na forma de gravações dos comportamentos evidentes dos projetistas e participantes das reuniões, como gravações de verbalizações, esboços e audiovisuais capturados pelas câmeras de gravação em vídeo.

Com base na observação das reuniões de coordenação em processos BIM e tradicional, e na análise da literatura e das normas vigentes em relação à ergonomia da relação humano-sistema (ABNT, 2011a, 2011b), foram levantadas as necessidades dos usuários, considerando os aspectos a seguir como importantes para o levantamento desses dados:

(a) identificar os usuários da sala;

(b) identificar um conjunto de características desses usuários (conhecimentos, habilidades, experiência, formação, treinamento, aptidões);

(c) identificar os objetivos e tarefas dos usuários dentro da sala;

(d) identificar características relevantes do ambiente físico, social e cultural dos usuários; e

(e) especificar os requisitos dos usuários (necessidades dos usuários, contexto de uso, ergonomia, interação, mobiliário, infraestrutura, espaço e conforto ambiental).

A partir desse levantamento foram definidos critérios e métricas objetivas para as principais necessidades dos usuários. Essas métricas foram aplicadas em quatorze propostas de leiaute para uma mesma sala disponível para o estudo. Esses leiautes continham a mesma quantidade de mesas, cadeiras e telas de projeção e acomodavam o mesmo número de usuários. Para que essas variáveis pudessem ser comparadas equilibradamente, foi aplicado o método Analytic Hierarchy Process (AHP) (SAATY, 1990) sobre critérios e subcritérios. Os leiautes foram classificados de acordo com a análise multicritério. Por fim, quatorze leiautes foram testados em uso para avaliar o método de avaliação proposto.
Os resultados foram analisados e chegou-se à conclusão sobre os ajustes necessários ao método proposto e, entre os leiautes avaliados, quais eram os mais indicados para uso na sala estudada para fins de realização de reuniões de coordenação BIM, levando-se em consideração os critérios ligados à visualização, interatividade e espaço físico, que são aqueles que variam em função do leiaute dos móveis e equipamentos no ambiente físico (ADDOR; SANTOS, 2015).

\section{Resultados e discussão}

\section{Levantamento das necessidades para usuários de reuniões em BIM}

Com base na observação de 100 h de gravação em vídeo de reuniões de coordenação de projetos em processo convencional e de 10 reuniões de coordenação em processo BIM (ADDOR; SANTOS, 2014), bem como na análise de bibliografia e das normas técnicas vigentes, foram levantados requisitos dos usuários para uma sala de coordenação em processo BIM, conforme detalhado na seção Método de Pesquisa.

O levantamento completo de todas as necessidades de um usuário de uma sala de coordenação em BIM foi elaborado e tomou como base a interação do usuário com o espaço e os recursos (humanos, físicos ou informacionais), considerando ações que demandassem infraestrutura relacionada a esses recursos.

Em um primeiro momento foram identificadas mais de cem necessidades, que, após analisadas do ponto de vista de afinidades de ações, foram aglutinadas em ações semelhantes, o que reduziu a lista para uma classificação de apenas seis necessidades básicas dos participantes de reuniões de coordenação em BIM. Essas atividades, descritas a seguir, poderiam influenciar na determinação do leiaute de uma sala de coordenação, conforme a Tabela 1 .

Tabela 1 - Necessidades dos usuários das salas BIM

\begin{tabular}{c|c|l}
\hline Interface & Tipo de Interação & \multicolumn{1}{c}{ Necessidade } \\
\hline Física & Pessoa-Equipamento & Visualização de informações \\
Física & Pessoa-Pessoa & Interatividade \\
Física & Equipamento-Espaço & Infraestrutura elétrica e rede \\
Física & Pessoa-Mobiliário & Mobiliário \\
Física & Mobiliário-Espaço & Espaço físico \\
Física & Pessoa-Espaço & Conforto ambiental \\
\hline
\end{tabular}




\section{Visualização de informações}

Necessidade de todos os participantes visualizarem um projeto, uma imagem, um texto, uma planilha de dados ou um vídeo por meio de um dispositivo de visualização.

\section{Interatividade}

Necessidade de comunicação e interação interpessoal entre os participantes, de modo que eles possam enxergar uns aos outros e se comunicar.

\section{Infraestrutura elétrica/rede}

Necessidade que a sala deve atender para energizar e conectar equipamentos externos de participantes, tais como notebooks, tablets e smartphones.

\section{Mobiliário}

Necessidade que a sala deve satisfazer a fim de proporcionar conforto e assento aos usuários e apoio para equipamentos externos e objetos pessoais, tais como notebooks, caderno de anotações e tablets.

\section{Espaço físico}

Necessidade que a sala deve satisfazer com relação ao espaço necessário para a circulação dos usuários, disposição do mobiliário e espaço para assento das pessoas.

\section{Conforto ambiental}

Parâmetros mínimos necessários de iluminação, temperatura e acústica para que os usuários possam participar com conforto de uma reunião.

\section{Definição de critérios e métricas para avaliação de leiautes}

Para cada uma das seis necessidades dos usuários levantadas anteriormente foram propostos critérios ligados a seu atendimento e métricas para mensurar o desempenho de um leiaute relativo a cada critério. Esse conjunto de métricas, ao serem combinadas de forma ponderada, permite a avaliação de alternativas de leiautes que atendem melhor ou pior às necessidades identificadas. Os critérios e métricas propostos são descritos abaixo.

\section{Necessidade 1 (visualização de informações)}

Para avaliação ao atendimento desta necessidade foram estabelecidos três critérios e respectivas métricas referentes ao relacionamento entre o participante da reunião e a tela de projeção onde são mostradas as informações.

\section{Critério 1.1}

Para visualização confortável da tela, o ângulo horizontal $(A)$ com que o observador tem que girar o olho, a cabeça e/ou o corpo para enxergar toda a área de visualização deve ser pequeno. Para que um observador não precise mexer o olho ao visualizar algum objeto ou imagem, o ângulo de visualização a partir do centro da imagem é da ordem de, no máximo, 20 graus para cada lado (campo de visão binocular). Se essa variação estiver entre 20 e 35 graus, o observador terá que mexer o olho. Se for entre 35 e 55 graus, terá que mexer a cabeça, e se maior que 55 graus terá que girar o corpo ou a cadeira em que estiver sentado para que possa enxergar todo o objeto visualizado - no caso, toda a tela de projeção (PANERO; ZELNIK, 1979).

\section{Métrica 1.1}

Deve ser traçado um par de retas imaginárias desde o centro da cabeça do participante até as arestas verticais da esquerda e direita da tela (se forem duas telas justapostas, considerar a largura total das duas). $\mathrm{O}$ ângulo $A$ entre essas duas retas é medido desde a posição de cada um dos participantes e categorizado de acordo com as faixas $\mathrm{A} \leq 40^{\circ} ; 40^{\circ}<\mathrm{A} \leq 70^{\circ} ; 70^{\circ}<\mathrm{A} \leq 110^{\circ}$ e $\mathrm{A}>110^{\circ}$ (Figura 1). Os limites dessas faixas foram definidos de acordo com os padrões ergonômicos apresentados no critério 1.1, considerando o ângulo total do campo de visão em cada caso. As faixas de valores foram introduzidas para não diferenciar leiautes que, na prática, têm o mesmo desempenho nesse critério.

\section{Critério 1.2}

A porcentagem de oclusão da tela percebida pelo observador a partir de seu posicionamento na sala, considerando os móveis, equipamentos e corpos dos demais participantes, deve ser pequena. Para avaliar-se sob este critério, a métrica adotada foi a porcentagem da tela bloqueada pelos corpos dos demais participantes (supondo um manequim padronizado) e outros elementos, a partir do ponto de vista do participante considerado (Figura 2). 
Figura 1 - Aplicação da métrica de ângulo horizontal
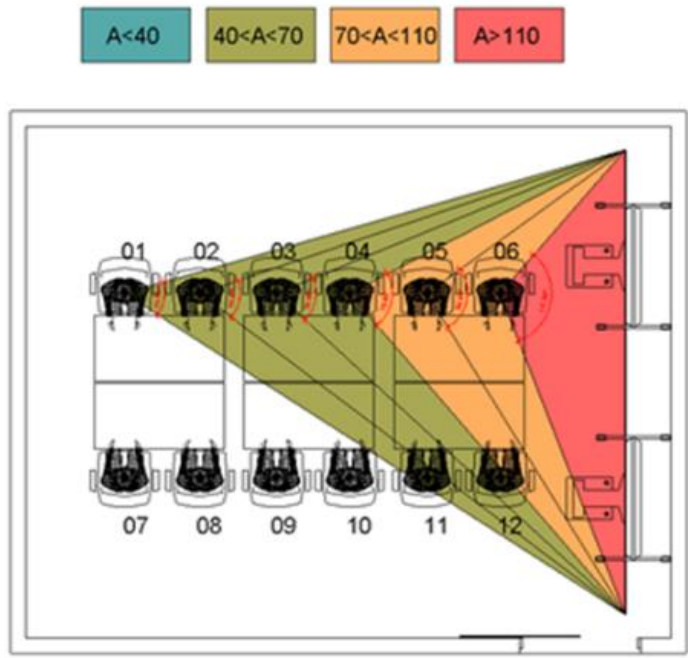

Figura 2 - Geração de imagem em aplicativo 3D a partir do ponto de vista de um participante

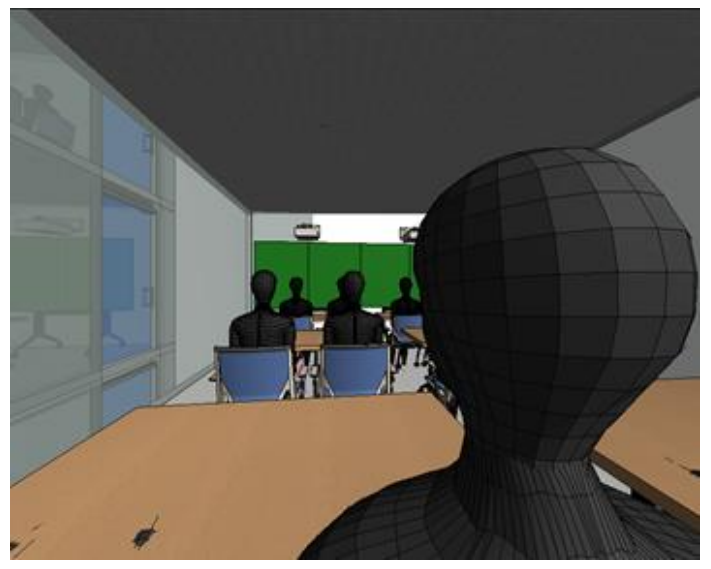

\section{Métrica 1.2}

Para fazer essa medição, imagens do ambiente a partir da posição da cabeça de cada participante, e com a tela preenchida com cor diferenciada, são geradas em aplicativo de modelagem 3D e exportadas para aplicativo de tratamento e análise de imagens, em que são contadas as quantidades de pixels ocultos e não ocultos na região da tela (ferramenta de histograma) (Figura 3). Da relação entre as duas áreas é calculada a porcentagem de oclusão da tela. Em vez de modelo virtual, é possível a utilização de fotografia da sala com participantes típicos, porém esse processo é mais demorado e trabalhoso. As porcentagens foram categorizadas em quatro faixas de obstrução, a partir da análise de alguns resultados preliminares: $0-5 \% ; 5,1-10 \% ; 10,1-15 \%$; e $>15 \%$.

\section{Critério 1.3}

O máximo ângulo vertical entre a aresta superior da tela e a horizontal na altura do olho do observador deve ser pequeno. Ângulo até $30^{\circ}$ (para frente ou para trás com a cabeça) representa movimento confortável. Ângulos de até $50^{\circ}$ para trás e $40^{\circ}$ para frente são os máximos ângulos de movimento vertical para a cabeça humana (PANERO, ZELNIK; 1979). Ângulos maiores requerem movimento do tronco.

\section{Métrica 1.3}

Para o cálculo da métrica correspondente, em planta traçou-se a linha de corte do usuário em relação ao centro da tela. Em uma vista em corte, traça-se uma linha perpendicular da altura do olho do usuário até o centro da tela de projeção e outra até a aresta superior da tela (Figura 4). Mede-se o ângulo $\alpha$ entre essas linhas. Os ângulos são categorizados em faixas: $0^{\circ}<\alpha \leq 30^{\circ} ; 30^{\circ}<\alpha \leq 50^{\circ}$; e $\alpha>50^{\circ}$, de acordo com o critério ergonômico. 
Figura 3 - Análise da imagem em aplicativo de tratamento de imagem

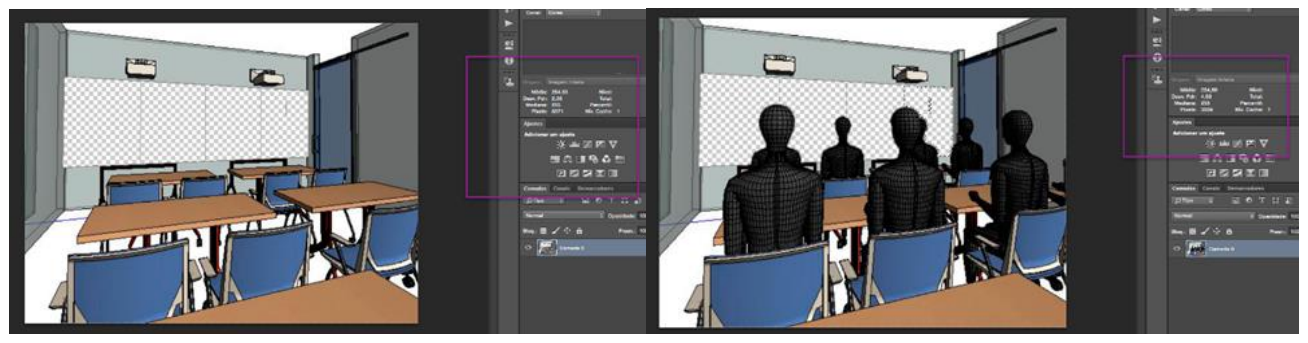

Figura 4 - Medição do máximo ângulo vertical

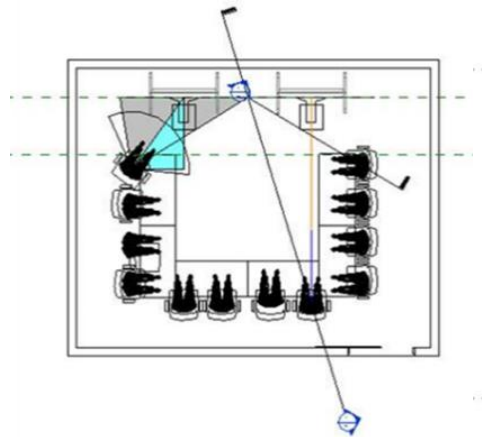

\section{Necessidade 2 (interatividade)}

Considerando que, numa reunião, os participantes devem interagir (conversar), para esta necessidade foram estabelecidos critérios ligados à facilidade de interação entre os participantes da reunião.

\section{Critério 2.1}

A conversação é facilitada quando os participantes podem enxergar uns aos outros diretamente, a sua frente ou a seu lado, sem obstáculos que obstruam a visão da face do outro.

\section{Métrica 2.1}

Para medição da obstrução do participante foi considerada uma linha reta entre a cabeça do locutor e a cabeça do interlocutor. Se entre esses dois pontos houver outro participante, considerase a existência de obstrução. Se não houver obstrução, atribui-se zero à medição, e, se houver obstrução, atribui-se valor 1 à medição, conforme a Figura 5Fehler! Verweisquelle konnte nicht gefunden werden.

\section{Critério 2.2}

A conversação é facilitada quando os interlocutores estão próximos.

\section{Métrica 2.2}

Para avaliação da distância entre interlocutores $d$, mede-se a distância entre um par de participantes
(Figura 6), classificada em quatro faixas: até 1,40 m; de 1,41 m a 2,40 m; de 2,41 m a 3,00 m; e acima de $3,00 \mathrm{~m}$. A referência para essa métrica foi obtida em estudo observacional nas reuniões de coordenação de projeto relatadas anteriormente.

\section{Critério 2.3}

A conversação é mais confortável quando os interlocutores estão frente a frente; menos confortável quando estão lado a lado; e desconfortável quando um está atrás do outro.

\section{Métrica 2.3}

O ângulo $a$ que o locutor tem que girar para interagir com o interlocutor (olhar face a face) é medido (Figura 7). Foram consideradas quatro faixas de classificação: $0^{\circ}<\mathrm{a} \leq 45^{\circ} ; 45^{\circ}<\mathrm{a} \leq 90^{\circ}$; $90^{\circ}<\mathrm{a} \leq 135^{\circ}$; e $135^{\circ}<\mathrm{a} \leq 180^{\circ}$.

\section{Necessidade 3 (infraestrutura)}

O critério estabelecido para esta necessidade diz respeito à quantidade de tomadas de uso geral que há na sala para ligar os equipamentos portáteis dos participantes da reunião.

\section{Critério 3.1}

Cada participante eventualmente precisa de uma tomada para ligar um notebook (celular pode ser recarregado na porta USB do notebook, se necessitar energizar ambos os equipamentos). 
Figura 5 - Avaliação de obstrução entre participantes

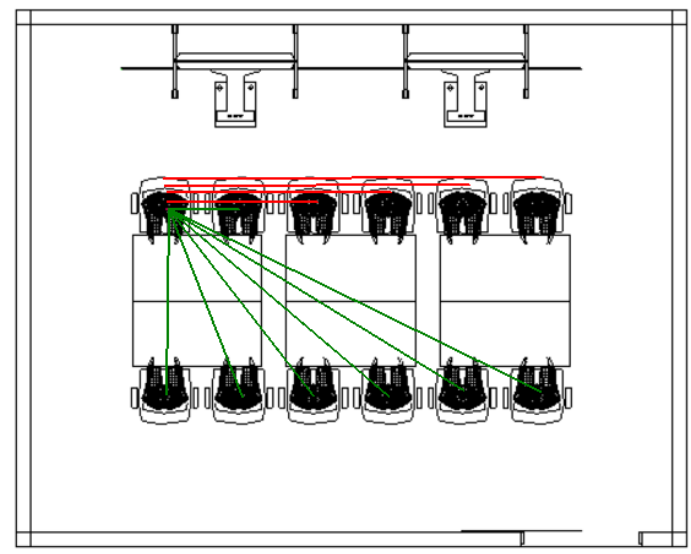

Figura 6 - Medição de distância
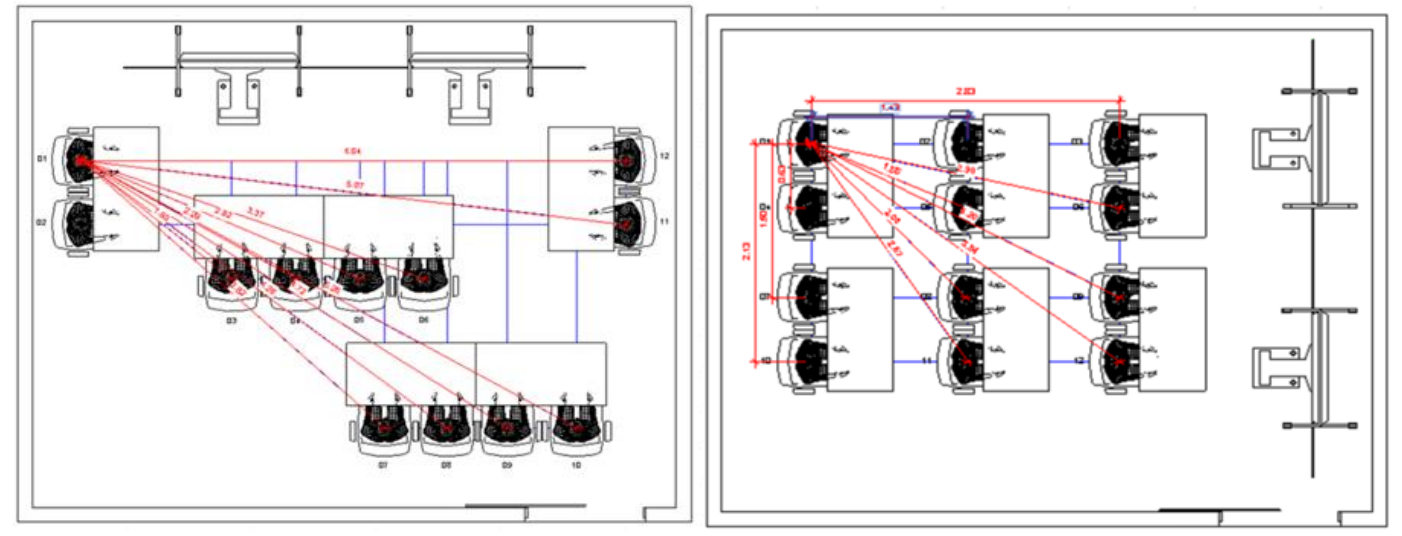

Figura 7 - Medição de ângulo

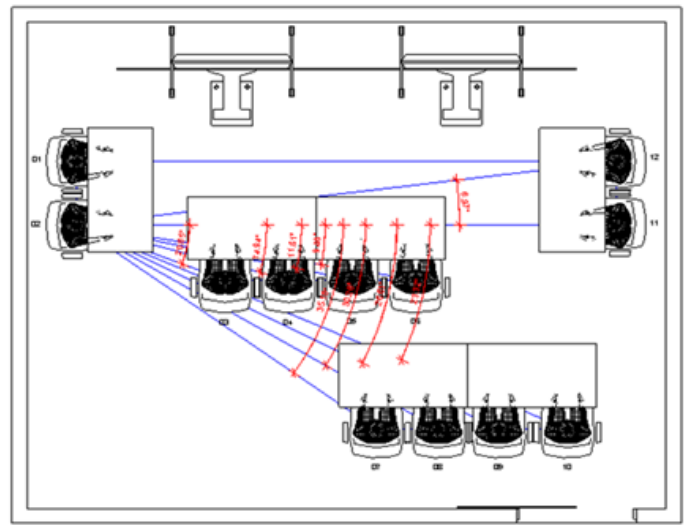

Métrica 3.1

A métrica consiste na simples contagem do número de tomadas disponíveis ao alcance do total de participantes quando em suas posições de trabalho. Foram consideradas três faixas: menos que $1 / 2$ tomada por pessoa; $1 / 2$ tomada por pessoa; $\mathrm{e}$ 1 tomada por pessoa. A referência utilizada para estabelecimento dessa métrica foi o estudo

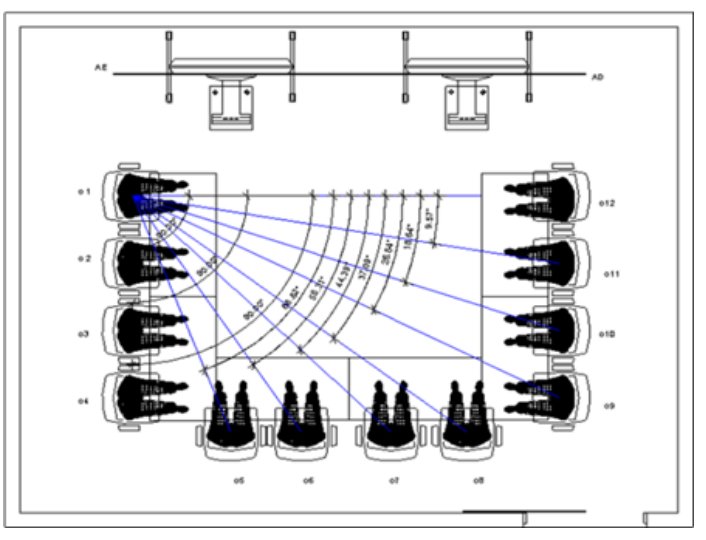

observacional em reuniões de coordenação de projetos.

\section{Necessidade 4 (mobiliário)}

Os participantes em uma reunião de coordenação BIM têm necessidade de suporte físico para apoiar materiais de referência e equipamentos portáteis durante a reunião. 


\section{Critério 4.1}

O critério estabelecido para esta necessidade diz respeito ao tamanho do apoio para equipamentos portáteis trazidos pelos participantes da reunião. A referência mínima foi baseada em uma carteira escolar com dimensões de $37 \mathrm{~cm}$ de largura por 33 $\mathrm{cm}$ de profundidade, referente a uma base mínima de apoio para um notebook.

\section{Métrica 4.1}

A métrica é feita através das dimensões da área destinada a cada participante (mesmo que não delimitada fisicamente) na mesa de trabalho. Foram definidas três faixas para a classificação, com medidas de largura e profundidade: LxP $<37 x 33 \mathrm{~cm} ; 37 \times 33 \mathrm{~cm}<\operatorname{LxP}<80 x 61 \mathrm{~cm}$; e LxP>81x62 cm (PANERO; ZELNIK, 1979).

\section{Necessidade 5 (espaço físico)}

Deve-se prever espaço de circulação para os participantes deslocarem-se nos locais de reunião. Os espaços de circulação deverão ser adequados, evitando-se a interrupção das atividades na sala e possíveis acidentes durante a passagem causados por fios, pés de mesa, suportes de equipamento, etc.

\section{Critério 5.1}

Deve haver espaço suficiente para que os participantes possam chegar até seu assento desde a entrada da sala, bem como permitir que possam sair de suas posições e deslocarem-se até a tela interativa e retornar sem a necessidade de movimentação de outros participantes.

\section{Métrica 5.1}

A métrica estabelecida é a distância $D$ entre o encosto da cadeira com uma pessoa sentada até o objeto ou anteparo mais próximo atrás dela (Figura 8). As distâncias de circulação encontradas são classificadas em quatro faixas: $>1,0 \mathrm{~m}$; entre $1,0 \mathrm{~m}$ e $0,8 \mathrm{~m}$; entre $0,8 \mathrm{~m}$ e $0,6 \mathrm{~m}$; e menor que $0,6 \mathrm{~m}$ (DIFFRIENT; TILLEY; BARDAGJY, 1979).

\section{Necessidade 6 (conforto ambiental)}

Os participantes das reuniões precisam de conforto ambiental para desempenhar satisfatoriamente suas funções. As questões relativas a conforto ambiental não influenciam diretamente o leiaute de uma sala de reuniões, no entanto devem ser consideradas como necessidades dos usuários e constam como critério de análise.

\section{Critério 6.1}

Deve haver conforto térmico, acústico e lumínico para os participantes na sala de reuniões de coordenação.

\section{Métrica 6.1}

Temperatura confortável na sala de reuniões (entre $20{ }^{\circ} \mathrm{C}$ e $\left.23{ }^{\circ} \mathrm{C}\right)$ deve ser garantida (MINISTÉRIO..., 2007), bem como o nível de ruído não deve ultrapassar a faixa de $30-40 \mathrm{~dB}(\mathrm{~A})$ (ABNT, 1987). A velocidade do ar não deve ser superior a $0,75 \mathrm{~m} / \mathrm{s}$ (MINISTÉRIO..., 2007), a umidade relativa do ar não inferior a $40 \%$ (MINISTÉRIO..., 2007), e deve haver iluminação natural ou artificial adequada a uma sala de reunião em torno de 500 lux de luminância, 19 $\mathrm{UGR}_{\mathrm{L}}$ de limite de ofuscamento unificado, e $80 \mathrm{Ra}$ de índice de reprodução de cor mínimo (ABNT, 2013). As condições de conforto são ou não são atendidas, de acordo com as normas citadas.

\section{Figura 8 - Medição de espaço físico}

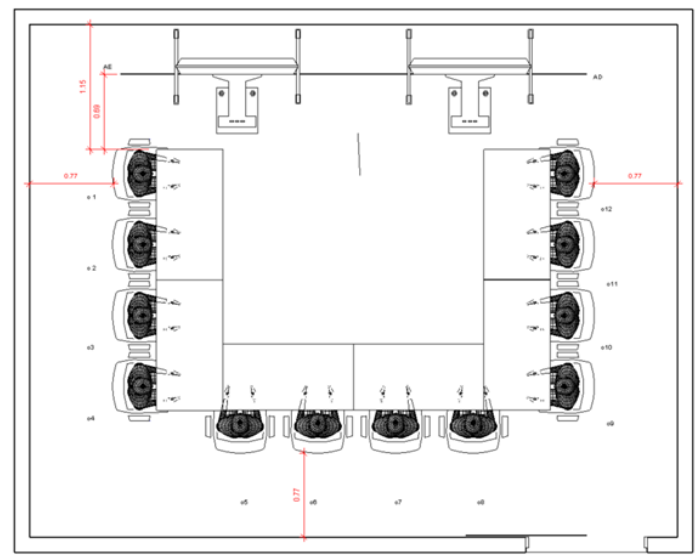




\section{Definição de leiautes para o estudo}

Para o presente estudo foram definidos catorze tipos de cenários para ser testados dentro dos critérios estabelecidos e as métricas que os avaliam. Para essa composição foram considerados os elementos relativos aos participantes, o mobiliário e o equipamento (hardware e software). Os leiautes foram propostos pelos autores com base em observação de ocorrência em salas de coordenação e outros para teste da metodologia. Ao se observarem os leiautes L2, L8 e L12, verifica-se que eles têm pessoas sentadas de costas para uma das telas de projeção. Obviamente essa não é a posição indicada para uma sala de coordenação de projetos; no entanto, esses leiautes aparecem dessa forma para averiguação das métricas e critérios propostos. O espaço escolhido foi uma sala de reuniões de 5,96 m x 4,71 m que estava disponível para o estudo e na qual já eram realizadas reuniões de coordenação de projetos. Nela foram posicionadas 6 mesas de dimensões 1,20 m (comprimento) x $0,60 \mathrm{~m}$ (largura) x $0,77 \mathrm{~m}$ (altura), 12 cadeiras e 2 projetores interativos com telas de 96" em suportes móveis, para atender a 12 participantes. Os leiautes propostos estão representados na Figura 9.

\section{Avaliação de leiautes com os critérios e métricas propostas}

Foram selecionados sete critérios e respectivas métricas para avaliação dos leiautes idealizados, sendo os três de visualização (1.1 a 1.3), os três de interatividade (2.1 a 2.3) e o de espaço físico (5.1). Esses sete critérios selecionados têm métricas dependentes do leiaute, ao passo que infraestrutura (3.1), mobiliário (4.1) e conforto ambiental (6.1) são variáveis independentes desse fator, mantendo-se inalterados, já que a sala física avaliada (dimensões, iluminação, infraestrutura e condicionamento ambiental) bem como seu mobiliário foram mantidos constantes.

As métricas foram aplicadas aos catorze leiautes propostos. Todos os dados foram registrados em planilhas eletrônicas, como no exemplo da Figura 10, que mostra a medição de ângulos horizontais (métrica 1.1) para cada um dos 12 participantes da reunião, bem como a classificação em faixas de valores.

Figura 9 - Leiautes avaliados

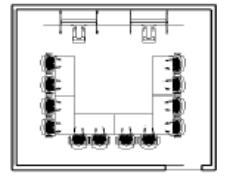

L1

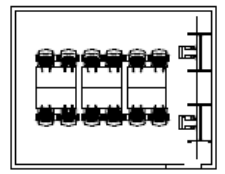

L5

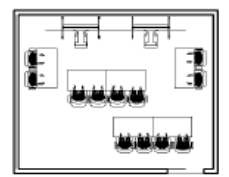

L9

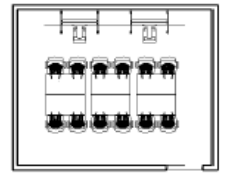

$\mathrm{L} 2$

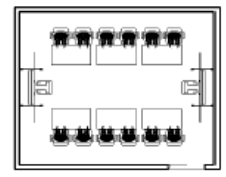

L6

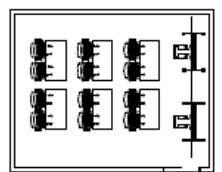

L10

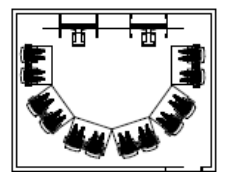

$\mathrm{L} 13$

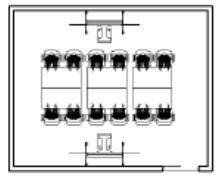

L3

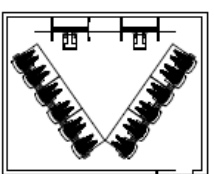

L7

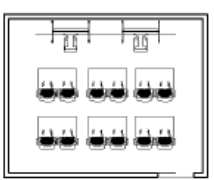

L11

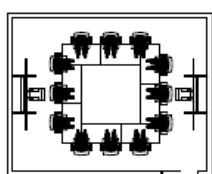

L14

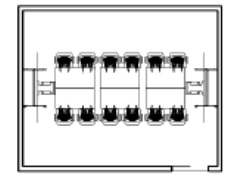

L4

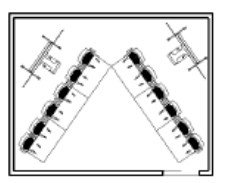

L8

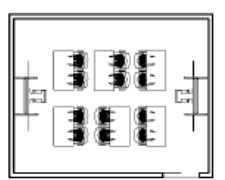

L12 
Figura 10 - Medição de ângulo

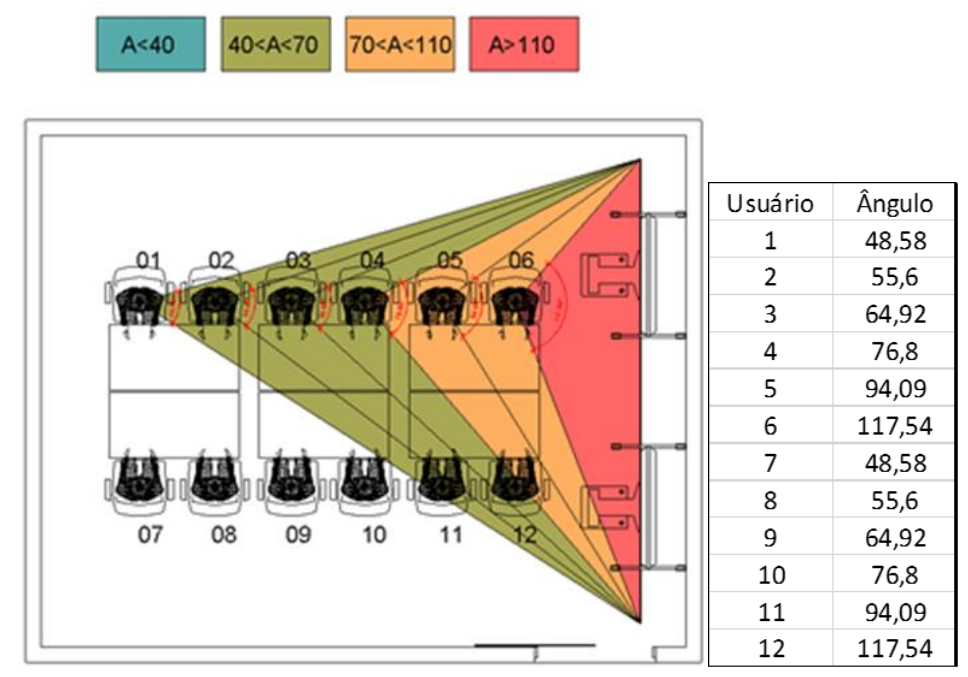

\section{Análise multicritério com aplicação de AHP ${ }^{1}$ para composição das métricas}

Com o propósito de entender qual a importância relativa entre todas as necessidades e critérios definidos neste trabalho, foi aplicado o método de decisão multicritério Analytic Hierarchy Process (AHP) (SAATY, 1990). Neste trabalho o objetivo final da aplicação do método AHP é a obtenção de uma fórmula que permite, através de uma nota global, ranquear as várias alternativas de leiaute propostas para uma sala, determinando-se a(s) melhor(es). A composição dessa nota é feita pela soma ponderada do desempenho do leiaute em diferentes aspectos (especificamente as necessidades levantadas). Cada necessidade tem uma importância relativa diferente aos olhos dos usuários para o cumprimento das funções de uma sala de coordenação. Assim, por exemplo, boa visualização da tela poderia ser considerada muito mais importante que adequado espaço de circulação. Da mesma forma, os critérios estabelecidos para avaliação do atendimento a cada uma das necessidades têm importância relativa diferente, que necessita ser determinada em função da opinião dos usuários típicos a que se destina a sala. Por fim, a medição e o cálculo das métricas foram mapeados em faixas de valores que não necessariamente mantêm entre si uma relação linear entre medida e qualidade ou contribuição ao desempenho. Necessidades, critérios e faixas de valores devem ser adequadamente ponderados para a composição de uma nota global que represente o mérito de uma alternativa de sala de coordenação BIM.
Assim, de acordo com o método AHP, para se determinarem os pesos relativos dos vários itens que compõem a nota global de uma alternativa, foram levantadas as opiniões de dez participantes de reuniões de coordenação de projeto. Esses participantes, que responderam às comparações AHP, foram selecionados de forma a manter aproximadamente a proporção típica de sua presença em reuniões de projeto (ADDOR; SANTOS, 2014): 4 coordenadores de projeto, 4 projetistas e 2 compatibilizadores de projeto. Todos tinham experiência prévia com BIM e já haviam participado de reuniões de coordenação em BIM. Os participantes foram informados sobre as regras de preenchimento das comparações par a par, utilizando-se a escala fundamental proposta por Saaty (1990) (Tabela 2).

Após a realização de uma reunião de coordenação em BIM, os dez participantes foram orientados a preencher planilhas como a ilustrada na Figura 11. Preencheram-se planilhas de comparação par a par das necessidades, critérios e faixas de valor.

\section{Determinação do vetor de prioridades de cada nível da hierarquia}

As opiniões de cada um dos dez participantes da reunião foram analisadas em todos os níveis hierárquicos de composição da nota global. Para melhor entendimento dos diversos níveis da hierarquia AHP, foi construído o gráfico da Figura 12.

${ }^{1}$ Analytic Hierarchy Process. 
Tabela 2 - Escala fundamental AHP

\begin{tabular}{c|l|l}
\hline \multicolumn{2}{c}{ Tabela: Escala Fundamental de Saaty (1980) } \\
\hline 1 & $\begin{array}{l}\text { Igual importância } \\
\text { Importância pequena de } \\
\text { uma sobre a outra } \\
\text { Importância grande ou } \\
\text { essencial } \\
\text { Importância muito } \\
\text { grande ou demonstrada }\end{array}$ & $\begin{array}{l}\text { As duas atividades contribuem igualmente para o } \\
\text { objetivo. } \\
\text { A experiência e o juízo favorecem uma atividade em } \\
\text { relação à outra. } \\
\text { A experiência ou juízo favorece fortemente uma } \\
\text { atividade em relação à outra. } \\
\text { Uma atividade é muito fortemente favorecida em } \\
\text { relação à outra. Pode ser demonstrada na prática. } \\
\text { A evidência favorece uma atividade em relação à } \\
\text { outra, com o mais alto grau de segurança. } \\
\text { Quando se procura uma condição de compromisso } \\
\text { entre duas definições. }\end{array}$ \\
\hline
\end{tabular}

Fonte: adaptada de Saaty (1980).

Figura 11 - Planilha de comparação de necessidades, par a par

\begin{tabular}{c|c|c|c|c|c|c}
\hline & Visualização & Interatividade & Infraestrutura & Mobiliário & Espaço & $\begin{array}{c}\text { Conforto } \\
\text { Ambiental }\end{array}$ \\
\hline $\begin{array}{c}\text { Visualização } \\
\text { Interatividade } \\
\text { Infraestrutura } \\
\text { Mobiliário } \\
\text { Espaço }\end{array}$ & 1 & 1 & & & & \\
Conforto & & & 1 & 1 & 1 & \\
Ambiental & & & & & & 1 \\
\hline
\end{tabular}

Figura 12 - Níveis hierárquicos para análise multicritério

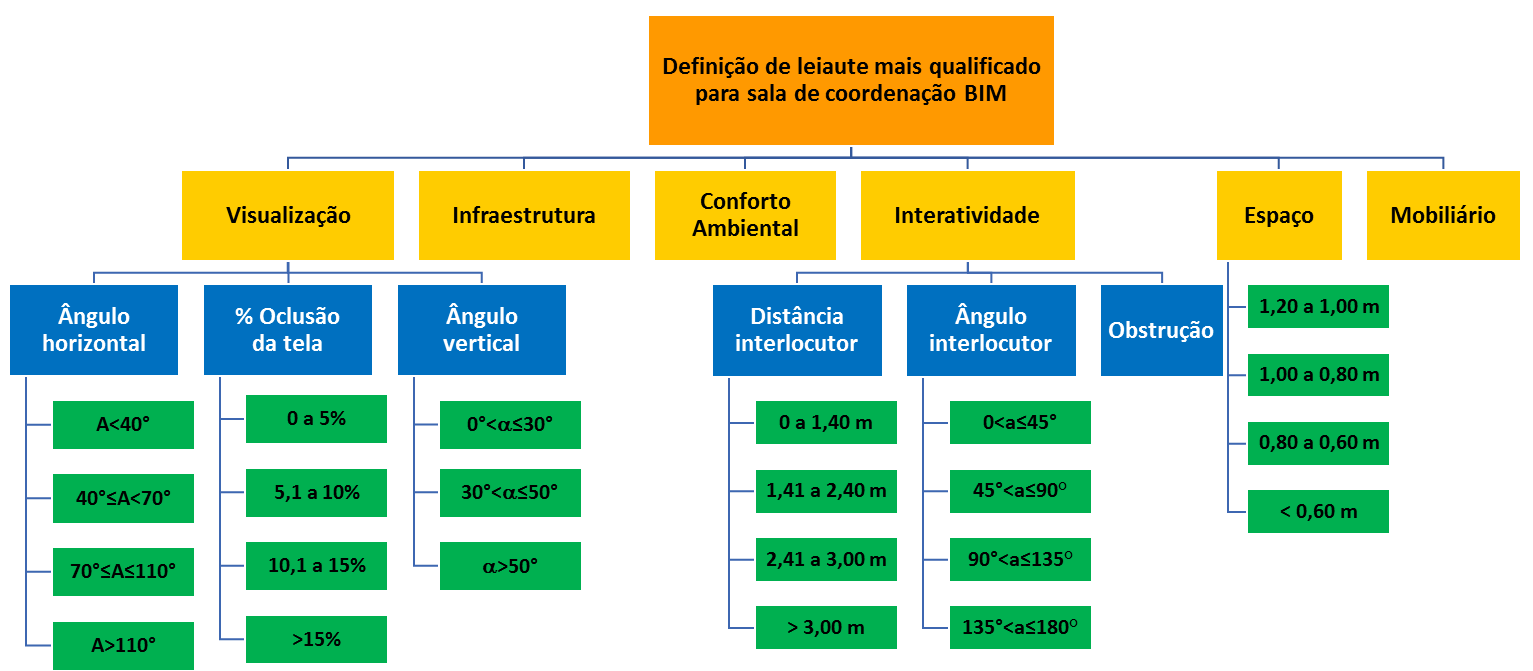

As opiniões das dez pessoas entrevistadas foram analisadas de acordo com a técnica de Saaty (1990): para identificar o vetor de prioridades de cada uma das matrizes geradas pela comparação par a par, foram calculados os autovalores e autovetores de cada uma das matrizes preenchidas (Figura 10). Antes de se processar cada matriz, foi necessário verificar sua consistência, já que os julgamentos dos participantes são subjetivos. Saaty (1990) determinou, através de dois teoremas, que, se o maior autovalor real $\left(\chi_{\max }\right)$ fosse igual ao número de componentes de uma matriz quadrada, então essa matriz seria considerada consistente. No entanto, nem sempre isso ocorre. Então, o autor determinou o índice de 
consistência (CI - consistency index) de uma matriz quadrada adotando a Equação 1:

$\mathrm{CI}=\chi_{\max }-\mathrm{n} /(\mathrm{n}-1)$,

Eq. 1

Onde:

$\chi_{\max }$ : maior autovalor real da matriz; e

$\mathrm{n}$ : ordem da matriz.

Saaty (1990) sugere também o uso da razão de consistência (CR - consistency ratio), que é uma relação entre o CI e o índice randômico (RI random index), que varia de acordo com o tamanho da matriz (SAATY, 1980). O índice randômico foi proposto a partir de várias experiências de laboratório na Wharton School, de matrizes de ordem 1 a 15, conforme a Tabela 3 .

A razão de consistência (CR) de uma matriz é dada por CI/RI. Uma razão de consistência até $10 \%$ é considerada aceitável, conforme Saaty (1980). Caso contrário, o mesmo autor recomenda que os julgamentos sejam refeitos até que a consistência aumente. Assim, foram calculados os autovalores e autovetores de cada uma das matrizes, sendo considerados somente os de valores reais. Foram calculados os índices de consistência (CI) e as respectivas razões de consistência $(\mathrm{CR})$ para cada matriz preenchida, e verificado se ela era consistente $(\mathrm{CR}<10 \%)$, sendo reajustada a comparação em caso de necessidade.

Após a análise de todas as matrizes de um dado critério, métrica ou faixa, foi feita a média dos valores encontrados a partir da normalização das opiniões dos dez respondentes e encontrado o vetor das prioridades que compõem determinada necessidade ou critério. Esse vetor de prioridades contém valores ou pesos que serão atribuídos às medições ou critérios em cada leiaute avaliado.

As necessidades visualização, interatividade, infraestrutura, mobiliário, espaço e conforto ambiental foram comparadas duas a duas pelos dez entrevistados. Os fatores de maior influência sobre a qualidade do leiaute foram: visualização, com $37,5 \%$ de influência, seguido pela interatividade, com $27,3 \%$ de influência.
A mesma comparação dois a dois foi realizada pelos participantes para os critérios ligados à visualização e à interatividade (segundo nível na hierarquia, Figura 12). O principal parâmetro de influência sobre o leiaute na visualização foi a porcentagem de oclusão da tela, com 55,7\%. Entre os critérios ligados à interatividade, o fator "ângulo que o observador tem que girar para interagir com outro observador" teve a maior prioridade $(42,5 \%)$. A Tabela 4 contempla os pesos obtidos para os critérios e os valores normalizados para as faixas das métricas.

\section{Classificação dos leiautes de acordo com a análise multicritério}

Nesta fase da pesquisa as medições nos leiautes obtidas através das métricas foram mapeadas em valores normalizados de acordo com os vetores de prioridade estabelecidos na análise multicritério (Tabela 4). A opinião média dos dez avaliadores indicou a nota proporcional entre as faixas de ângulos estabelecidas.

A nota final de um leiaute num dado critério é calculada pela média das notas normalizadas das métricas atribuídas naquele critério para cada posição na sala (no caso, 12 participantes/posições). Esse procedimento foi aplicado para todos os catorze leiautes em relação a todas as métricas.

\section{Análise dos leiautes de acordo com as classificações multicritério}

Após o estabelecimento dos fatores de prioridade das necessidades e critérios pela análise AHP, as alternativas de leiaute foram analisadas. Para cada um dos leiautes, em cada uma das métricas, foi extraída a média aritmética das notas normalizadas obtidas. Por exemplo, de acordo com a métrica ângulo horizontal de visualização, o leiaute mais bem avaliado foi o 13, e os piores, 3, 4, 6, 12 e 14 (estes com a mesma nota), conforme a Tabela 5 e a Figura 13.

Tabela 3 - Índice randômico médio em função da ordem da matriz

\begin{tabular}{c|c|c|c|c|c}
\hline Ordem & $\mathbf{1}$ & $\mathbf{2}$ & $\mathbf{3}$ & $\mathbf{4}$ & $\mathbf{5}$ \\
\hline RI & 0,00 & 0,00 & 0,58 & 0,90 & 1,12 \\
Ordem & $\mathbf{6}$ & $\mathbf{7}$ & $\mathbf{8}$ & $\mathbf{9}$ & $\mathbf{1 0}$ \\
RI & 1,24 & 1,32 & 1,41 & 1,45 & 1,49 \\
Ordem & $\mathbf{1 1}$ & $\mathbf{1 2}$ & $\mathbf{1 3}$ & $\mathbf{1 4}$ & $\mathbf{1 5}$ \\
RI & 1,51 & 1,48 & 1,56 & 1,57 & 1,59 \\
\hline
\end{tabular}

Fonte: adaptada de Saaty (1980). 
Tabela 4 - Resumo das médias dos vetores de prioridades das necessidades, critérios e métricas

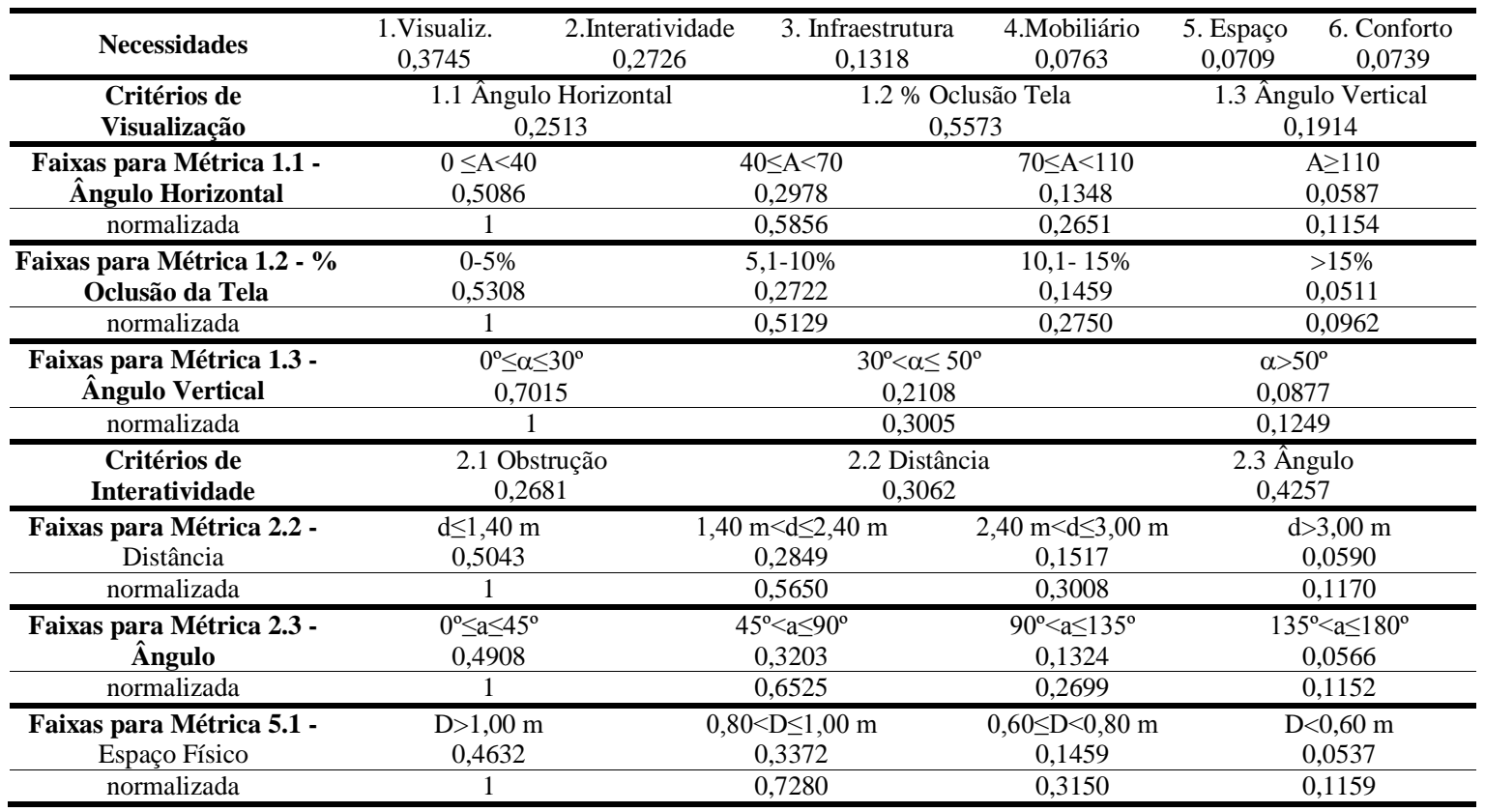

Tabela 5 - Média das notas obtidas por cada leiaute para a métrica "ângulo horizontal"

\begin{tabular}{|c|r|}
\hline LEIAUTE & ÂNGULO \\
\hline 13 & 0,58562 \\
\hline 1 & 0,47878 \\
\hline 7 & 0,47878 \\
\hline 9 & 0,47878 \\
\hline 10 & 0,47878 \\
\hline 11 & 0,42536 \\
\hline 5 & 0,40042 \\
\hline 2 & 0,29712 \\
\hline 8 & 0,14040 \\
\hline 3 & 0,11546 \\
\hline 4 & 0,11546 \\
\hline 6 & 0,11546 \\
\hline 12 & 0,11546 \\
\hline 14 & 0,11546 \\
\hline
\end{tabular}


Figura 13 - 0 melhor leiaute avaliado (L13) e os piores em relação à métrica “ângulo horizontal”

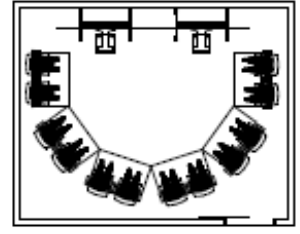

L13

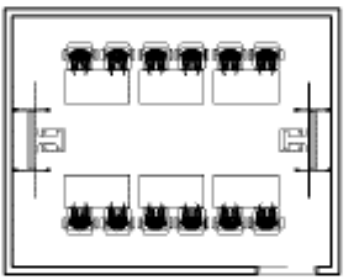

L6

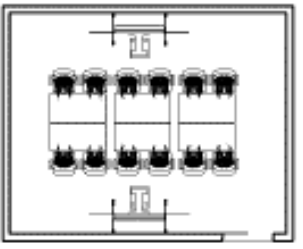

L3

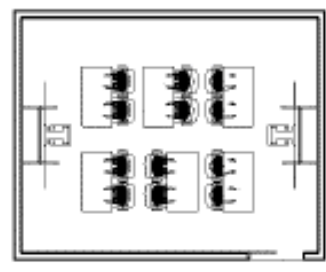

$\mathrm{L} 12$

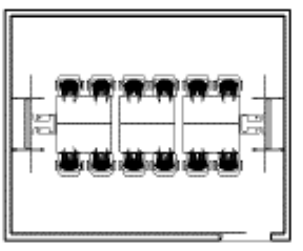

L4

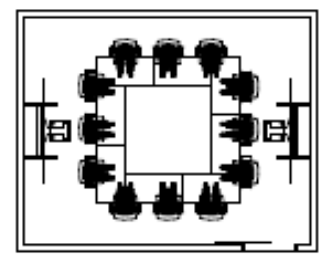

L14
E, por fim, após o cálculo das notas globais considerando todas as necessidades identificadas, chegou-se ao resultado da classificação final no nível hierárquico mais alto da AHP - necessidades de visualização, interatividade, infraestrutura, mobiliário, espaço e conforto ambiental, apresentado na Tabela 6.

De acordo com os resultados, os três leiautes que receberam as maiores notas foram o $\mathrm{L} 7$, com nota 0,81 , seguido do leiaute L13, com nota 0,79 , e, em terceiro, o L9, com nota 0,74 , conforme as Figuras 14 e 15 .

\section{Avaliação do método}

Para avaliar o método proposto (composto de critérios ponderados e métricas), ele foi testado na avaliação de sete leiautes. Foram escolhidos para teste empírico os quatro que obtiveram melhor nota, além do leiaute L1, e também o leiaute L14 (situação intermediária), e o pior leiaute classificado, o L12. Esses leiautes foram submetidos a uso durante reuniões de coordenação em BIM. As reuniões ocorreram dentro da sala com as dimensões propostas na teoria. Os leiautes dos móveis e equipamentos foram arranjados de acordo com a proposta de cada leiaute. As reuniões foram integradas por 12 participantes, sendo 4 coordenadores de projeto, 6 projetistas e 2 compatibilizadores de projeto. Foram realizadas sete reuniões BIM pelas mesmas pessoas, na mesma sala, com o mesmo mobiliário e os mesmos equipamentos, cada uma organizada segundo um dos leiautes selecionados. A variável de observação do estudo foi a modificação do leiaute. Após cada reunião, foi entregue a cada participante uma planilha para avaliação do leiaute. A planilha continha as necessidades ligadas ao leiaute avaliadas na teoria, e os leiautes podiam receber notas de 1 (péssimo) a 5 (excelente), referentes ao atendimento de cada uma das necessidades. Após o preenchimento das planilhas, foi calculada a soma das notas de cada participante para cada leiaute. Ao final, foi calculada a média ponderada das notas de todos os participantes para aquele leiaute.

Os participantes das reuniões foram informados de que o leiaute seria avaliado ao final da reunião, e os critérios para avaliação foram expostos de forma que aqueles pudessem ficar atentos durante a reunião. A Tabela 7 mostra as notas obtidas para a análise dos leiautes na teoria (método proposto) e na prática (opinião de usuários) para os critérios visualização, interatividade e espaço físico.

A Tabela 8 apresenta o resultado da classificação global dos leiautes considerando a composição ponderada de todas as necessidades, através das notas pelos usuários ("uso") e por aquelas obtidas através do método proposto ("método"). 
Tabela 6 - Resultado final da classificação dos leiautes

\begin{tabular}{|c|r|r|r|r|r|r|r|}
\hline Layout & VISUALIZAÇÃo & INTERATIVIDADE & $\begin{array}{c}\text { INFRAEST. } \\
\text { ELÉTRICA E } \\
\text { REDE }\end{array}$ & MOBILIÁRIO & ESPAÇO & $\begin{array}{l}\text { CONFORTO } \\
\text { AMBIENTAL }\end{array}$ & TOTAL \\
\hline 1 & 0,231135666 & 0,161851773 & 0,131799107 & 0,076319941 & 0,022334 & 0,073905716 & 0,697346 \\
\hline 2 & 0,232610551 & 0,161225962 & 0,131799107 & 0,076319941 & 0,051614 & 0,073905716 & 0,727476 \\
\hline 3 & 0,198882513 & 0,162525334 & 0,131799107 & 0,076319941 & 0,038522 & 0,073905716 & 0,681955 \\
\hline 4 & 0,121534153 & 0,161498098 & 0,131799107 & 0,076319941 & 0,0709 & 0,073905716 & 0,635957 \\
\hline 5 & 0,173240631 & 0,161498098 & 0,131799107 & 0,076319941 & 0,0709 & 0,073905716 & 0,687663 \\
\hline 6 & 0,291254304 & 0,154783246 & 0,131799107 & 0,076319941 & 0,008218 & 0,073905716 & 0,73628 \\
\hline 7 & 0,325447022 & 0,153328539 & 0,131799107 & 0,076319941 & 0,049144 & 0,073905716 & 0,809945 \\
\hline 8 & 0,173039925 & 0,154372749 & 0,131799107 & 0,076319941 & 0,039502 & 0,073905716 & 0,648939 \\
\hline 9 & 0,295892805 & 0,146404978 & 0,131799107 & 0,076319941 & 0,018665 & 0,073905716 & 0,742988 \\
\hline 10 & 0,220408727 & 0,1237941 & 0,131799107 & 0,076319941 & 0,012923 & 0,073905716 & 0,639151 \\
\hline 11 & 0,261311133 & 0,130591494 & 0,131799107 & 0,076319941 & 0,022334 & 0,073905716 & 0,696261 \\
\hline 12 & 0,185187075 & 0,116532164 & 0,131799107 & 0,076319941 & 0,008218 & 0,073905716 & 0,591962 \\
\hline 13 & 0,335501932 & 0,153127223 & 0,131799107 & 0,076319941 & 0,021018 & 0,073905716 & 0,791672 \\
\hline 14 & 0,197356193 & 0,166799632 & 0,131799107 & 0,076319941 & 0,015276 & 0,073905716 & 0,661456 \\
\hline
\end{tabular}

Figura 14 - Classificação final dos leiautes de acordo com os critérios e métricas aplicados

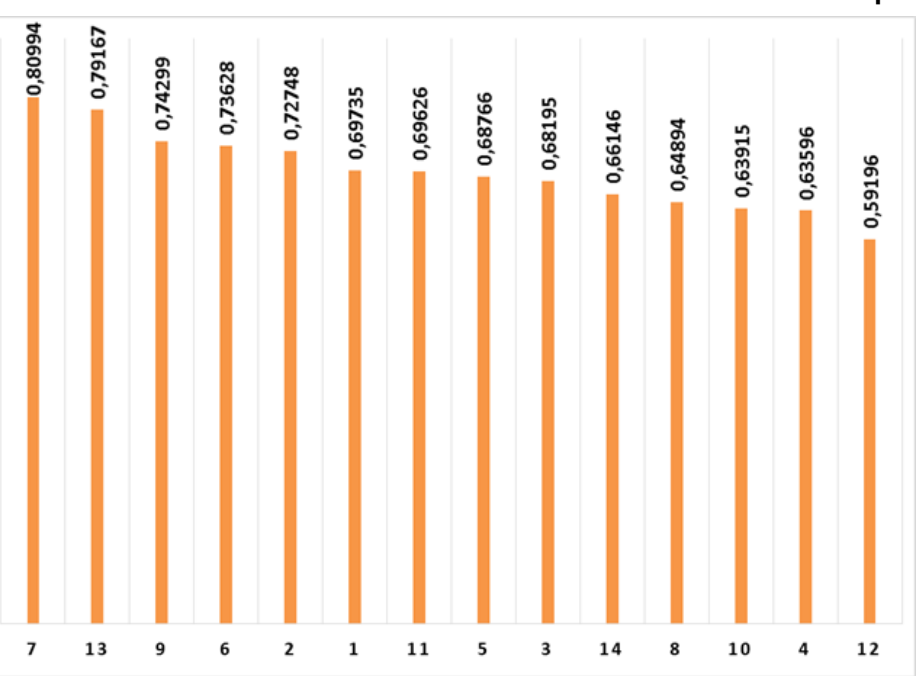

Figura 15 - Os quatro melhores leiautes classificados de acordo com os critérios
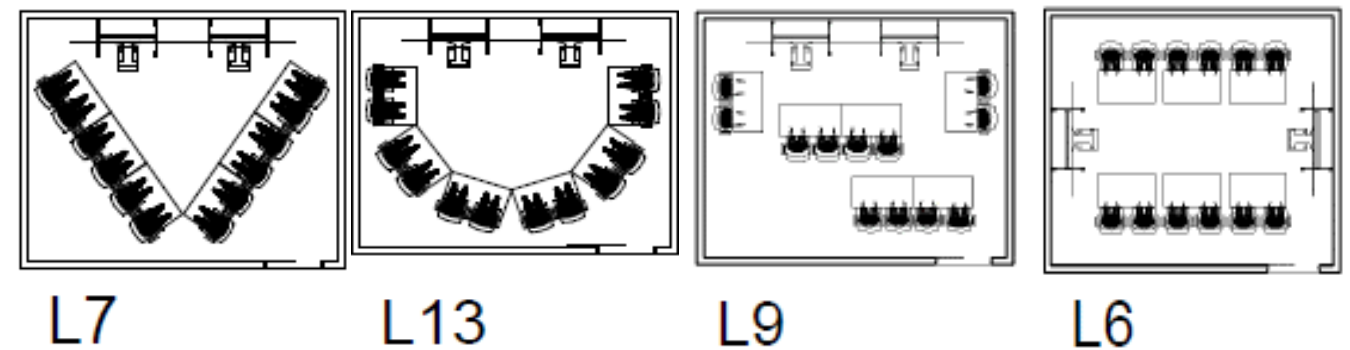
Tabela 7 - Ordenamento dos leiautes em função de cada uma das necessidades

\begin{tabular}{|c|c|c|c|}
\hline \multicolumn{2}{|c|}{ EM USO } & \multicolumn{2}{|c|}{ PELO MÉTODO } \\
\hline LEIAUTE & VISUALIZAÇÃO & LEIAUTE & VISUALIZAÇÃO \\
\hline L1 & 1,7142 & L13 & 0,3355 \\
\hline L13 & 1,7142 & L7 & 0,3254 \\
\hline L7 & 1,6207 & L9 & 0,2959 \\
\hline L9 & 1,4648 & L6 & 0,2913 \\
\hline L6 & 1,2778 & L1 & 0,2311 \\
\hline L14 & 1,0597 & L14 & 0,1974 \\
\hline L12 & 0,6545 & L12 & 0,1852 \\
\hline \multicolumn{2}{|c|}{ EM USO } & \multicolumn{2}{|c|}{ PELO MÉTODO } \\
\hline LEIAUTE & INTERATIVIDADE & LEIAUTE & INTERATIVIDADE \\
\hline L14 & 1,2949 & L14 & 0,1668 \\
\hline L13 & 1,2267 & L1 & 0,1619 \\
\hline L1 & 1,2040 & L6 & 0,1548 \\
\hline L7 & 1,0450 & L7 & 0,1533 \\
\hline L6 & 1,0223 & L13 & 0,1531 \\
\hline L9 & 0,5452 & L9 & 0,1464 \\
\hline L12 & 0,4089 & $\mathbf{L 1 2}$ & 0,1165 \\
\hline \multicolumn{2}{|c|}{ EM USO } & \multicolumn{2}{|c|}{ PELO MÉTODO } \\
\hline LEIAUTE & ESPAÇO & LEIAUTE & ESPAÇO \\
\hline L14 & 0,2895 & L7 & 0,0491 \\
\hline L1 & 0,2659 & L1 & 0,0223 \\
\hline L6 & 0,2600 & L13 & 0,0210 \\
\hline L9 & 0,2186 & L9 & 0,0187 \\
\hline L12 & 0,2068 & L14 & 0,0153 \\
\hline L13 & 0,1773 & L6 & 0,0082 \\
\hline L7 & 0,1536 & L12 & 0,0082 \\
\hline
\end{tabular}

Tabela 8 - Ordenamento final dos leiautes, avaliados pelos usuários e pelo método proposto

\begin{tabular}{|c|c|c|c|}
\hline \multicolumn{2}{|l|}{ uso } & \multicolumn{2}{|c|}{ método } \\
\hline 3,1862 & L1 & 0,5279 & L7 \\
\hline 3,1202 & L13 & 0,5096 & L13 \\
\hline 2,8210 & L7 & 0,4610 & L9 \\
\hline 2,6463 & L14 & 0,4543 & L6 \\
\hline 2,5619 & L6 & 0,4153 & L13 \\
\hline 2,2298 & L9 & 0,3794 & L14 \\
\hline 1,2711 & L12 & 0,3099 & L12 \\
\hline
\end{tabular}

Entre os sete leiautes testados em uso, o L1 empatado com o L13 obtiveram a melhor classificação em visualização, sendo que pelo método o L1 aparece como o quinto classificado e o L13 como o primeiro colocado em visualização. Analisando os resultados parciais do L1 pelo método, constata-se que ele recebeu a pior nota na composição da visualização em relação à oclusão da tela. Dessa forma, sugere-se uma melhor averiguação na calibragem das faixas adotadas para a métrica de oclusão no método. Coloca-se em questionamento se ter $5 \%$ de oclusão é 10 vezes melhor que ter $15 \%$ de oclusão. Na análise teórica do L1, os 3 participantes que se encontram sentados de lado em relação à tela, logo após o participante que está mais próximo a ela, receberam a nota mais baixa de oclusão para interação, o que, no entanto, não se refletiu no uso do leiaute. Ao mesmo tempo, o L13, na análise teórica, recebeu notas altas em função de sua oclusão ser $0 \%$, ou seja, se não há oclusão as demais métricas parecem compatíveis entre a teoria e a prática, indicando um desvio pontual neste quesito.

Para a necessidade interatividade, o L14 foi o mais bem avaliado tanto em prática quanto em teoria. Esse fato pode mostrar que as métricas de ângulo, distância e oclusão entre os interlocutores e locutores estão mais calibradas. Outro fator que corrobora esse fato é o L1 ter ficado em terceiro lugar em uso e segundo em teoria de acordo com a interatividade, o que mostra mais uma vez a boa aferição das faixas de análise das métricas. 
Para a necessidade espaço houve grande discrepância entre a avaliação em uso, com o L14 em primeiro lugar, sendo que em teoria o L14 se encontra em quinta posição. Esse fato pode indicar que as métricas de espaço poderiam ser recalibradas no método, procurando restringir mais as medidas e, portanto, adequá-las a um uso mais consciente do espaço. Um outro indicativo que esta métrica deve ser recalibrada é o fato de o L7 ter ficado em primeira colocação quando analisado pelo método. Este leiaute é do tipo "V", e, portanto, a média da distância das cadeiras à parede está dentro de faixas mais confortáveis estabelecidas pela métrica.

Entre os sete leiautes avaliados em uso, o L1 obteve a melhor classificação, sendo que, pelo método, o L7 é o que obteve o primeiro lugar tanto na classificação geral quanto entre os sete avaliados. No entanto, o L1 aparece como quinto classificado quando avaliado pelo método. Mais uma vez as métricas que desfavorecem o L1 em relação ao L7 em teoria são o fator de oclusão e o espaço.

\section{Conclusões}

Este estudo apresentou a proposta de um método para avaliação da qualidade de salas de coordenação BIM, bem como a avaliação dele.

O estudo revelou que a determinação das notas para os leiautes nos vários critérios permitiu perceber os pontos fortes e fracos de cada um no atendimento às necessidades dos usuários da sala de reuniões.

No entanto, percebeu-se que as necessidades dos usuários têm caráter conflitante em relação a aspectos da configuração da sala, isto é, ao procurar atender melhor a uma delas, piora-se o desempenho em relação a outra necessidade. Mais ainda, nem sempre é evidente qual de duas alternativas atende melhor a dado critério.

De acordo com a aplicação do método proposto, as classificações dos leiautes se alternaram dependendo do critério que estivesse sendo considerado. Quando a análise enfocou o ângulo horizontal (necessidade de mexer os olhos, cabeça ou corpo) para visualizar algo na tela, os leiautes em formato de " $U$ " redondo ou quadrado ou em "V" foram os melhores (leiautes L13, L1 e L7), pois os participantes da reunião se encontravam mais de frente para as telas, o que facilitava a visualização. Consistentemente, leiautes com participantes de costas para a tela, como é o caso do L14 e L12, tiveram notas piores, pois implicam a movimentação maior do participante para visualizar imagens na tela. Para validação do método proposto, esse tipo de leiaute foi incluído na análise a fim de se verificar a aderência das métricas propostas, que respondeu exatamente como se esperava, validando-as. Para a análise e teste do método foram consideradas sempre imagens diferentes projetadas nas duas telas (isto é, a necessidade de visualização de ambas por todos os participantes). No caso dos leiautes L4 e L6, que, apesar de não terem participantes de costas para a tela, têm um ângulo horizontal muito grande, pois as telas estão em lados opostos da sala, o grande ângulo de giro da cabeça abaixou muito suas notas nesse quesito.

$\mathrm{Na}$ classificação final, considerando todos os critérios, os dois leiautes melhor avaliados, com notas muito próximas, foram o L7 e L13 que, de acordo com os critérios estabelecidos pelo método foram os mais eficientes. A nota que proporcionou o pequeno desempate entre estes dois leiautes foi a métrica "espaço de circulação" que no L7 recebeu nota 2 vezes maior que o L13, após a atribuição da ponderação. Para a necessidade visualização, o L13 foi 1,5 vez melhor que o L7, em razão de os lugares muito próximos da tela gerarem notas mais baixas em relação ao ângulo horizontal com a tela. Então, pode-se dizer que, pela análise das métricas, leiautes em "U”, como o caso do L13, têm melhores resultados em visualização, com todas as notas melhores nos critérios e com obstrução entre os participantes nula. Em razão dessa proximidade muito grande em relação à classificação, em próximos estudos deve-se investigar mais a fundo as potencialidades de cada um desses leiautes. No entanto, dependendo do tipo de assunto da reunião de projeto, leiautes em "U" não têm boa nota em relação à distância entre o interlocutor e o locutor, pois em relação à métrica distância este foi o leiaute que recebeu a menor nota. Participantes que estão em uma ponta do "U" ficam muito distantes de participantes da outra ponta, o que contribuiu para a diminuição da nota.

Sete leiautes foram testados em uso durante reuniões de coordenação de projetos a fim de demonstrar que o método construído atende ao objetivo de avaliar salas de coordenação de projetos baseadas em BIM. Os resultados comparando opiniões em uso prático com as previstas pelo método proposto obtiveram, em geral, certa concordância. Identificou-se maior divergência dos resultados em relação à métrica oclusão ou, mais precisamente, na valoração das faixas de valores correspondentes a essa métrica, o que sugere sua revisão. Também para a métrica espaço de circulação houve significativa discrepância entre a avaliação em uso e a prevista pelo método proposto. A referência teórica para o estabelecimento desta métrica foi encontrada em literatura de quase 40 anos atrás. O uso do espaço contemporâneo pode indicar flexibilidade maior do usuário em relação às distâncias de uma cadeira a uma parede, ou mesmo 
de circulação, sugerindo uma readequação das faixas de classificação dessa métrica.

Dessa forma, pode-se sugerir que tanto essas duas métricas devam ser recalibradas quanto fazer uma avaliação com os participantes para verificar se estão sendo coerentes em suas avaliações. $O$ fato de a maioria dos participantes não ter tido a necessidade de se deslocar na sala durante a avaliação talvez tenha influenciado sua percepção sobre essa necessidade.

Por outro lado, é importante notar que a subjetividade é inerente ao método AHP, pois os participantes das reuniões registram suas impressões subjetivas dos leiautes de acordo com a escala proposta na metodologia. Para reduzir o grau de subjetividade, seria necessária grande quantidade de opiniões, para que haja convergência a uma média nas ponderações. Assim, possivelmente o melhor procedimento é analisar os resultados das métricas para os melhores leiautes, decidindo-se finamente de acordo com necessidades específicas, valores e convicções pessoais, em vez de confiar apenas num único número, resultado de todas as ponderações do AHP.

Os usuários da sala de coordenação de projeto digital estudados ainda não possuem um nível elevado de maturidade em relação a novas propostas de mídias tecnológicas. Acredita-se que, quanto mais esse tipo de mídia for sendo popularizada entre os projetistas, mais ela será apropriada por eles. O principal objetivo de uma reunião de coordenação de projeto, em geral, é a tomada de decisão sobre as questões do projeto, de forma objetiva e com qualidade. Nas salas de coordenação, além de se considerar a dificuldade ainda incipiente dos participantes com a nova tecnologia, deve-se considerar a importante separação da visualização do modelo durante a reunião e do controle e operação do software e hardware para que o modelo seja visualizado. Muitas vezes foi observado que os participantes acabam não se concentrando nas questões que realmente são necessárias (análise do projeto), pois estão envolvidos com as descobertas da tecnologia. A função da reunião é a discussão do projeto, e não a manipulação de softwares ou equipamentos, ou seja, o ser humano deve se concentrar na tarefa, e não na ferramenta. O ideal é que a sala promova essa interatividade sem maiores problemas aos usuários. Enfocando esta característica principal, a análise de projeto, indica-se que os leiautes classificados como mais eficientes nesta pesquisa possam ser aplicados em salas de coordenação nos escritórios de projetistas, construtoras, incorporadoras, escritórios de obras, e também nos laboratórios técnicos das universidades, enfocando a formação de engenheiros e arquitetos no processo BIM.

Apesar de esta investigação ter sido focada em espaços destinados a reuniões em BIM, entende-se que a aplicação do método proposto possa se estender aos demais processos de projeto digital que utilizem equipamentos de visualização e interação como forma de expressão dos projetos. Esses sistemas podem ser desde CAD 3D anteriores ao $\mathrm{BIM}$, como qualquer tipo de arquitetura que utilize a tecnologia da informação e comunicação. O método proposto, conforme relatado, pode ser mais bem calibrado, mas sua estratégia representa um avanço no campo da preparação de infraestrutura de uma sala de coordenação para projetos em BIM. Este trabalho acrescenta conhecimento a qualquer tipo de criação de um espaço de coordenação de projetos em BIM. As análises e avaliações desenvolvidas neste trabalho foram limitadas a salas equipadas apenas com mobiliário e dois projetores e telas de projeção. A avaliação de salas com mais equipamentos, como mesas interativas, tablets, câmeras, etc., requer expansão dos estudos para incorporar outros equipamentos. Alguns podem adotar as mesmas métricas e critérios já apresentados, porém novas análises devem ser conduzidas para levantamento dos pesos relativos num novo cenário. Outros tipos de equipamentos, devido a suas peculiaridades, podem demandar desenvolvimento de novos critérios e métricas, porém seguindo a mesma linha introduzida nesta pesquisa.

Como os participantes observados e consultados no decorrer desta pesquisa são todos atuantes somente no setor de empreendimentos imobiliários, as conclusões apresentadas limitam-se a esse ramo da construção. Porém, dadas as características da coordenação de projetos e o caráter genérico das métricas e critérios estabelecidos, acredita-se que os resultados possam se estender também a empreendimentos na área de infraestrutura.

\section{Referências}

ADDOR, M. R. A.; SANTOS, E. T. Infraestrutura Para Uma Sala de Coordenação de Projetos em BIM: avaliação dos padrões de comunicação e requisitos. In: ENCONTRO NACIONAL DE TECNOLOGIA DO AMBIENTE CONSTRUÍDO, 15., Maceió, 2014. Anais... Maceió: ENTAC, 2014. 
ADDOR, M. R. A.; SANTOS, E. T. Leiaute de Salas de Coordenação BIM: critérios e métricas de avaliação. In: ENCONTRO DE TECNOLOGIA DE INFORMAÇÃO E COMUNICAÇÃO NA CONSTRUÇÃO, 7.; EDIFICAÇÕES, INFRAESTRUTURA E CIDADE, DO BIM AO CIM, 11., Recife, 2015. Anais... Recife: 2015.

ASSOCIAÇÃO BRASILEIRA DE NORMAS TÉCNICAS. NBR ISO/CIE 8995-1: iluminação de ambientes de trabalho: parte 1: interior. Rio de Janeiro, 2013.

\section{ASSOCIAÇÃO BRASILEIRA DE NORMAS} TÉCNICAS. NBR ISO 9241-210: ergonomia da interação humano-sistema: parte 210: projeto centrado no ser humano para sistemas interativos. Rio de Janeiro, 2011a.

ASSOCIAÇÃO BRASILEIRA DE NORMAS TÉCNICAS. NBR ISO 9241-11: requisitos ergonômicos para o trabalho com dispositivos de interação visual: parte 11: orientações sobre usabilidade. Rio de Janeiro, 2011b.

ASSOCIAÇÃO BRASILEIRA DE NORMAS TÉCNICAS. NBR 10152: níveis de ruído para conforto acústico: procedimento. Rio de Janeiro, 1987.

DIFFRIENT, N.; TILLEY, A.; BARDAGJY, J. Humanscale 1/2/3: a portfolio of information. Cambridge: The MIT Press, 1979.

EASTMAN, C. et al. BIM Handbook: a guide to building information modeling for owners, managers, designers, engineers, and contractors. New Jersey: John Wiley \& Sons, 2008.

FISCHER, M. et al. Multi-Stakeholder Collaboration: the CIFE iRoom. In: CIB W78 CONFERENCE, Denmark, 2002. Proceedings... Denmark: Aarhus School of Architecture, 2002.

FRUCHTER, R. The Fishbowl: degrees of engagement in global teamwork. In: SMITH, I. F. C. Intelligent Computing in Engineering and Architecture. Berlim: Springer Verlag, 2006.

GOLPARVAR-FARD, M. et al. Requirements for a Mobile Interactive Workspace to Support Design Development and Coordination. In: JOINT INTERNATIONAL CONFERENCE ON COMPUTING AND DECISION MAKING IN CIVIL AND BUILDING ENGINEERING, 11. Montreal, 2006. Proceedings... Montreal: ASCE, 2006.

JIANG, H.; YEN, C. Protocol Analysis in Design Research: a review. In: INTERNATIONAL ASSOCIATION OF SOCIETIES OF DESIGN RESEARCH, Seoul, 2009. Proceedings... Seoul, 2009.
KASANEN, E.; LUKKA, K.; SIITONEN, A. The Constructive Approach in Management Accounting Research. Journal of Management Accounting Research, Sarasota, v. 5, p. 241-264, 1993.

KU, K. et al. 3D Model-Based Collaboration in Design Development and Construction of Complex Shaped Buildings. ITcon, v. 13, p. 258285, jun. 2008.

LEICHT, R. M. A Framework for Planning Effective Collaboration Using Interactive Workspaces. Pennsylvania, 2009. Ph.D. Thesis (Architectural Engineering) - Pennsylvania State University, State College, 2009.

LISTON, K.; FISCHER, M.; KUNZ, J.

Requirements and Benefits of Interactive Information Workspaces in Construction. In: INTERNATIONAL CONFERENCE AND COMPUTING IN CIVIL AND BUILDING ENGINEERING, 8., Stanford, 2000.

Proceedings... Stanford University, 2000.

LOPEZ, M. G. et al. Study and Analysis of Collaborative Design Practices. In: PARTICIPATORY INNOVATION CONFERENCE, Hague, 2015. Proceedings... Hague, 2015.

MCGRAW-HILL CONSTRUCTION. The Business Value of BIM in North America: multiyear trend analysis and user ratings (2007-2012). SmartMarket Report, 2012.

MCGRAW-HILL CONSTRUCTION. The Business Value of BIM for Construction in Major Global Markets: how contractors around the world are driving innovation with building information modeling. SmartMarket Report, 2014.

MELHADO, S. B. et al. (Coords.) Coordenação de Projetos de Edificações. São Paulo: O Nome da Rosa, 2005.

MINISTÉRIO DO TRABALHO E EMPREGO. NR-17: ergonomia. Brasília, 2007. Disponível em <http://www.guiatrabalhista.com.br/legislacao/nr/n r17.htm>. Acesso em: 15 abr. 2016.

OGUETA, C. M. S. User Innovation in digiTal Design and Construction: dialectical relations between standard BIM tools and specific user requirements. Cambridge, 2012. 147 f. Dissertação (Mestrado) - Massachusetts Institute of Technology, Cambridge, MA, 2012.

OYEGOKE, A. The Constructive Research Approach Management Research. International Journal of Managing Projects in Business, Bingley, v. 4, n. 4, p. 573-595, 2011. 
PANERO, J.; ZELNIK, M. Human Dimension \& Interior Space: a source book of design reference standards. New York: Watson-Guptill, 1979.

SAATY, T. L. The Analytic Hierarchy Process: planning, priority setting, resource allocation. Columbus: McGraw-Hill, 1980.

SAATY, T. L. How to Make a Decision: the analytic hierarchy process. European Journal of Operational Research, Amsterdam, v. 48, n. 1, p. 9-26, sept. 1990.

SANTOS, E. T. BIM - Building Information Modeling: um salto para a modernidade na tecnologia da informação aplicada à construção civil. In: PRATINI, E. F.; SILVA JUNIOR, E. A.

Criação, Representação e Visualização Digitais: tecnologias digitais de criação, representação e visualização no processo de projeto. Brasília: Faculdade de Tecnologia da Universidade de Brasília, 2012.

\section{SENESCU, R. R. Design Process}

Communication Methodology. Ph.D. Thesis

(Civil and Environmental Engineering) - Stanford University, 2011.

\section{Agradecimentos}

Os autores agradecem a Pedro Henrique Pedrosa Torres, por sua colaboração na coleta dos dados, à Financiadora de Estudos e Projetos (Finep) e ao Conselho Nacional de Desenvolvimento Científico e Tecnológico $(\mathrm{CNPq})$, por financiarem parte desta pesquisa, e aos avaliadores anônimos, pela contribuição à melhoria deste artigo.

Departamento de Engenharia de Construção Civil, Escola Politécnica | Universidade de São Paulo | Al. Vicente Pinzón $173,2^{\circ}$ andar, Vila Olímpia | São Paulo - SP - Brasil | CEP 04547-130 | Tel.: (11) 3045-0446 | E-mail: miriam@addor.com.br

\section{Eduardo Toledo Santos}

Departamento de Engenharia de Construção Civil, Escola Politécnica | Universidade de São Paulo | Av. Prof. Almeida Prado, n. 83, Trav. 2, Edif. de Engenharia Civil, Cidade Universitária | São Paulo - SP - Brasil | CEP 05508-070 | Tel.: (11) 3091-5284 |

E-mail: etoledo@usp.br

Revista Ambiente Construído

Associação Nacional de Tecnologia do Ambiente Construído

Av. Osvaldo Aranha, $99-3^{\circ}$ andar, Centro

Porto Alegre - RS - Brasil

CEP $90035-190$

Telefone: +55 (51) 3308-4084

Fax: +55 (51) 3308-4054

www.seer.ufrgs.br/ambienteconstruido

E-mail: ambienteconstruido@ufrgs.br 